
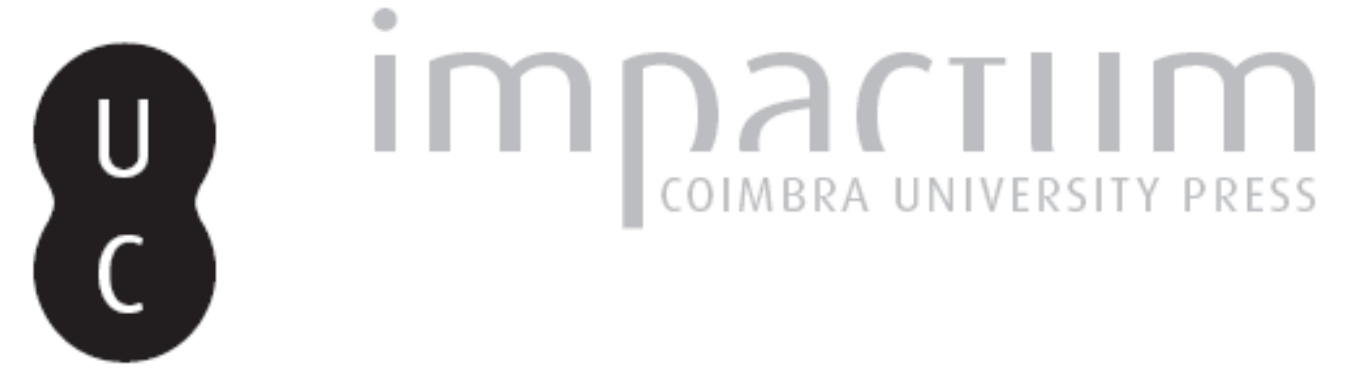

O nome que não ousa dizer da intimidade: um estudo exploratório sobre nomeação

Autor(es): $\quad$ Santos, Ana Lúcia; Santos, Ana Cristina

Publicado por: Imprensa da Universidade de Coimbra

URL persistente:

URI:http://hdl.handle.net/10316.2/43417

DOI:

DOI:http://doi.org/10.14195/2182-7982_34_1

Accessed : $\quad$ 26-Apr-2023 11:36:59

A navegação consulta e descarregamento dos títulos inseridos nas Bibliotecas Digitais UC Digitalis, UC Pombalina e UC Impactum, pressupõem a aceitação plena e sem reservas dos Termos e Condições de Uso destas Bibliotecas Digitais, disponíveis em https://digitalis.uc.pt/pt-pt/termos.

Conforme exposto nos referidos Termos e Condições de Uso, o descarregamento de títulos de acesso restrito requer uma licença válida de autorização devendo o utilizador aceder ao(s) documento(s) a partir de um endereço de IP da instituição detentora da supramencionada licença.

Ao utilizador é apenas permitido o descarregamento para uso pessoal, pelo que o emprego do(s) título(s) descarregado(s) para outro fim, designadamente comercial, carece de autorização do respetivo autor ou editor da obra.

Na medida em que todas as obras da UC Digitalis se encontram protegidas pelo Código do Direito de Autor e Direitos Conexos e demais legislação aplicável, toda a cópia, parcial ou total, deste documento, nos casos em que é legalmente admitida, deverá conter ou fazer-se acompanhar por este aviso.

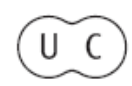




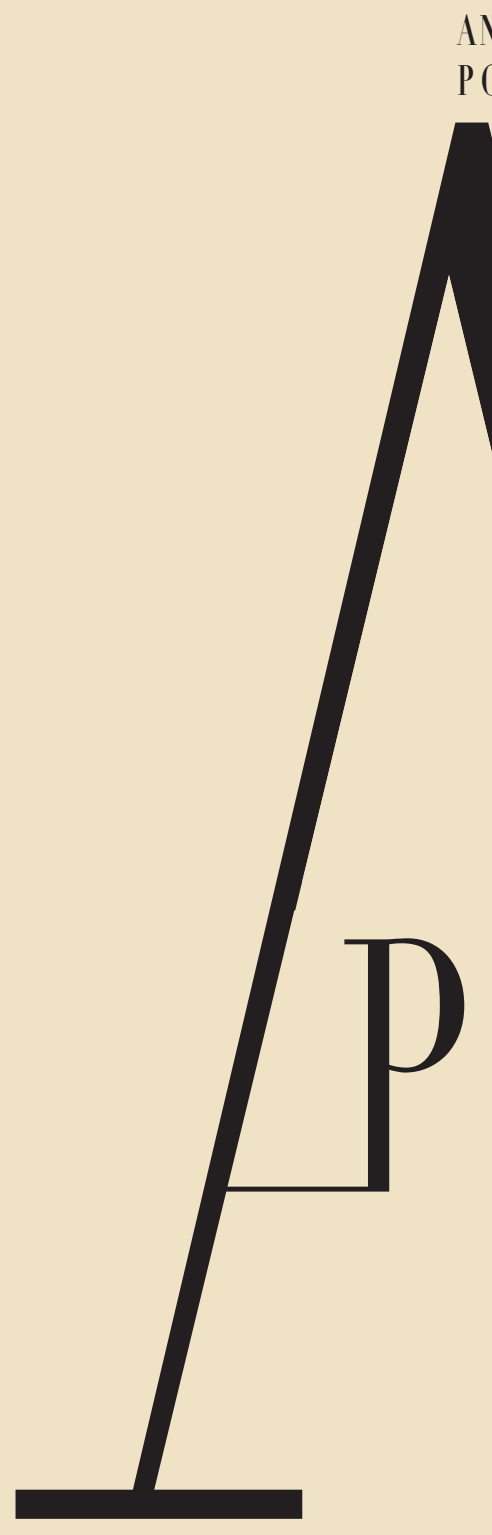

IITROPOLOGIA

PORTUGUESA 


\section{0 nome que não ousa dizer da intimidade — um estudo exploratório sobre nomeação}

\section{The name that dares not speak of intimacy — an exploratory study on naming}

\section{Ana Lúcia Santos ${ }^{1 \mathrm{1}^{*}}$, Ana Cristina Santos ${ }^{1 \mathrm{~b}}$}

\section{Resumo}

O processo de atribuição de nome corresponde a um guião cultural e jurídico que coloca entraves à autodeterminação de género, sexual e reprodutiva. Partindo de um estudo comparativo na Europa do Sul, neste artigo mapeamos transformações na lei portuguesa e auscultamos um conjunto de pessoas peritas em nomeação. O ponto focal do artigo consiste na perplexidade de um marco identitário pessoal que permanece refém de normatividades coletivas estritas, com forte impacto no terreno da cidadania íntima. Propõe-se que, no contexto português, o campo da nomeação constitui uma arena de assimetria, desigualdade e desidentificação, apontando-se para alternativas decorrentes de uma epistemologia crítica queer.

\begin{abstract}
The process of naming stems from a cultural and legal script that hinders gender, sexual and reproductive self-determination. Drawing on a comparative study in Southern Europe, this article maps out changes in Portuguese law and gathers voices of an array of experts on naming. The focus of the article is the perplexity resulting from a personal identity marker which remains hostage of restrictive collective rules that produce a significant impact on the sphere of intimate citizenship. We suggest that, in the Portuguese context, naming is a field of asymmetry, inequality and desidentification, and we advance alternatives framed by a critical queer epistemology.
\end{abstract}

${ }^{1}$ Centro de Estudos Sociais, Universidade de Coimbra.

* Corresponding author: analucia@ces.uc.pt

a orcid.org/0000-0001-5683-3886

${ }^{b}$ orcid.org/0000-0002-9597-7150

DOl: https://doi.org/10.14195/2182-7982_34_1

Artigo recebido a 28 de outubro de 2016 e aceite a 26 de abril de 2017 
Palavras-chave: Nomeação; identidade; cidadania íntima; binarismo de género; corpo; queer.

Não direi o teu nome como outrora pedi

\section{Introdução}

O nome é um elemento central da apresentação do eu na vida de todos os dias. Tal como demonstram estudos antropológicos sobre nomeação, o nome transporta consigo expectativas sociais que comportam elementos tão diversos quanto a nacionalidade, o género, a origem étnica, a herança religiosa ou a classe social (Breen, 1982; Durkheim e Mauss, 1984; Lopes da Silva, 1984; Bodenhorn e Vom Bruck, 2006; Pina-Cabral e Viegas, 2007a). Sendo um elemento simultaneamente privado e público, configura por excelência o terreno de reflexão feminista e queer em que nos situamos epistemologicamente e que tem como premissa de base a ideia de que o pessoal é político e que a intimidade é uma das componentes da cidadania (Plummer, 2003; Roseneil, 2010; Santos, 2013).

$\mathrm{O}$ interesse pelas políticas de atribuição de nome decorre da conjunção de vários fatores confluentes. Em primeiro
Keywords: Naming; identity; intimate citizenship; gender binary; body; queer.

lugar, apesar de constituir um elemento identitário central, em regra não participamos na escolha do nome que nos é atribuído e raramente desafiamos essa escolha na idade adulta. A exceção que se impõe a esta observação é protagonizada por pessoas transgénero, e aqui reside o segundo motivo de interesse acerca desta temática. De acordo com o Código de Registo Civil, os nomes não podem suscitar dúvidas em termos de género, o que reforça o binarismo masculino/feminino, sonegando o direito à autoidentificação com um género fluido ou neutro. Em terceiro lugar, apesar de a escolha do nome a atribuir a uma criança descrever um momento importante na biografia parental, essa escolha é condicionada por um guião tácito que visa disciplinar o nome pelo qual a nova cidadã ou cidadão encontrará espaço pessoal num contexto formal. A institucionalização do binarismo de género, por um lado, e do imaginário nacionalista, por outro, encontra aqui um dos seus terrenos mais férteis e menos questionados, quer pela academia, quer pelos movimentos sociais que dialogam com questões identitárias.

Foi esta combinação de fatores que levou a equipa de investigação do projeto INTIMATE a explorar o tema, de uma forma comparativa, em Portugal, Espanha e Itália, considerando, por um lado, a polí- 
tica de atribuição de nome a uma criança e, por outro, as possibilidades de escoIha ou de alteração de nome próprio em pessoas adultas. Neste artigo, centrado no caso português, começamos por revisitar as origens da onomástica enquanto campo a partir do qual a atribuição do nome passou a ser objeto de escrutínio jurídico. Na segunda parte, olhamos para a atribuição de nome a partir de uma lente que tem ficado ausente dos estudos antropológicos sobre nomes - a epistemologia crítica queer. Esta secção estará empiricamente ancorada num estudo exploratório realizado em Portugal entre abril e novembro de 2016, com cinco entrevistas semiestruturadas a um conjunto de agentes no terreno e pessoas peritas em nomeação, incluindo sociolinguistas, linguistas, consultores em onomástica da Conservatória dos Registos Gerais, decisores políticos e uma mãe de adolescente transgénero, que, por motivos de proteção de informação sensível, ficará ao abrigo do anonimato. O fio condutor que serve de guião às nossas perplexidades de partida é a proposta contida no título deste artigo e que vira do avesso a célebre frase de Óscar Wilde sobre o amor que não ousa dizer o seu nome. Com efeito, a partir da discussão suscitada no âmbito desta investigação, entramos no terreno das biografias que se escondem por trás da violência de um nome, um nome desidentificador, atribuído a partir de balizas estreitas que alimentam um regime de género e sexualidade normativo, disciplinador, e que subsidia processos mais amplos de discriminação sexual e reprodutiva num determinado contexto cultural. A heresia subjacente ao nome atribuído reside, conforme propomos já na reta final do artigo, nas múltiplas pertenças que invisibiliza, canalizando o sujeito para uma apresentação de si que não comporta um corpo mutante.

\section{Onomástica e práticas de atribuição de nome em Portugal}

Em maio de 2008, um casal heterossexual português deslocou-se a uma Conservatória do Registo Civil em Lisboa para registar a filha com o nome Mia. Este nome constava da lista de vocábulos não admitidos pelo Instituto dos Registos e do Notariado. O casal fez uma reclamação que foi reencaminhada para a Conservatória do Registo Civil de Lisboa. A Conservatória recorreu a um consultor, especialista em onomástica, que emitiu um parecer no qual declarava que Mia não podia ser aceite enquanto nome próprio, uma vez que contrariava a alínea a) do ponto 2 do artigo 103. do Código do Registo Civil (CRC), que determina que os nomes próprios devem ser portugueses, e uma vez que, no contexto português, o nome Mia apenas existe enquanto apelido. Apesar da consulta e respetivo parecer (procedimento não obrigatório nem vinculativo) a Conservatória decidiu contrariamente a este, argumentan- 
do, por sua vez, que, apesar de Mia não ser um nome próprio português, ainda conforme a mesma alínea do CRC, os nomes próprios (não portugueses) podem ser adaptados gráfica e foneticamente à língua portuguesa. Acrescentado o facto de Mia corresponder à 3. ${ }^{\text {a }}$ pessoa do singular do verbo "miar", a Conservatória entendeu estarem reunidas as condições suficientes para demonstrar que Mia é um vocábulo que partilha da grafia e fonética portuguesa, tal como Lia, além de ser um nome que já tinha sido requerido 11 vezes no passado, pelo que deveria ser aceite e incluído na lista de nomes permitidos (IRN, 2009a). Este exemplo demonstra de forma significativa a intransigência e a arbitrariedade da moldura normativa portuguesa em torno dos vocábulos admitidos para nomes próprios.

A onomástica é uma ciência do campo da linguística que estuda os nomes de lugares e de pessoas. Em Portugal, diferentemente daquilo que acontece na maioria dos países democráticos ocidentais, os vocábulos dos nomes próprios são regulados e não podem ser livremente escolhidos pelas pessoas que os requerem (Pinto, 2013). Apesar de não existir uma compilação oficial de nomes, existe uma lista disponibilizada pelo Instituto dos Registos e do Notariado (IRN) que reúne vocábulos admitidos e não admitidos para nome próprio, e que são, nas palavras do próprio IRN, "mais ou menos cientificamente elaborados" (IRN, 2009a: 3). Esta lista não reúne nomes próprios cuja admissibilidade seja inquestionável (tais como Ana), reunindo apenas aqueles que suscitaram dúvidas nas últimas décadas e que foram para consulta junto da Conservatória dos Registos Centrais (IRN, 2009b). Não sendo uma lista de nomes populares, alguns suscitam dúvidas em relação ao género gramatical, e por isso grande parte dos nomes faz-se acompanhar das letras " $M$ " ou " $F$ " para designar se determinado nome é do género masculino ou do género feminino. A lista atualizada (em 2016) contém cerca de 2600 nomes permitidos e 2700 nomes não permitidos. A observação que fizemos entre abril e junho de 2016 em fóruns online de mães e pais confirmou a hipótese de que a maior parte das pessoas participantes desconhece a existência desta lista. Tal desconhecimento leva a que, quando vão registar as suas crianças, possam enfrentar problemas pelo facto de o nome negociado e escolhido em contexto íntimo não constar da dita lista construída em contexto mais ou menos científico, parafraseando o IRN (2009a). Perante a impossibilidade de registo por falta de referência anterior, existe a possibilidade de o nome ser então estudado pela onomástica e posteriormente inserido na lista, enquanto admitido ou não admitido. Esta lista não é, portanto, estática, sendo até possível que um nome rejeitado num ano seja permitido no ano seguinte, conforme referido no caso "Mia". Em caso de requerimento de análise do nome, antes de este ser enviado para estudo onomástico, numa primeira fase, quem avalia a admissibilidade é, nas palavras de Paulo Pinto (2013: 5), "uma das 
centenas de funcionários de todo o país que está a atender o público, com base na sua memória, experiência e/ou conhecimento". Se a pessoa que está a atender não reconhecer o nome, pode então fornecer a lista de vocábulos permitidos e, caso não haja uma escolha de acordo com a dita lista, a Conservatória do Registo Civil faz um pedido de admissibilidade à Conservatória dos Registos Centrais, mediante o pagamento de 50 euros por parte do/a requerente. Se também nos Registos Centrais houver dúvidas quanto à admissibilidade do nome, esta Conservatória pode solicitar um parecer de um/a cientista ou técnico/a da Antroponímia (secção da onomástica dedicada aos nomes próprios), normalmente linguista, designado por "Consultor para Onomástica". Uma vez dado o parecer científico, cabe posteriormente à Conservatória dos Registos Centrais dar o veredicto final. Segundo Ivo Castro (2001: 6), cerca de 40\% dos nomes requeridos recebem parecer positivo'. Ainda que esta possibilidade

\footnotetext{
1 Em entrevista por nós conduzida (29/08/2016), o consultor de onomástica Ivo Castro confirmou que, dependendo da maneira como o nome é negociado no balcão, é possível ver-se aprovado o vocábulo pretendido. Também o consultor de onomástica João Silvestre confirma que a admissão ou rejeição de um nome na Conservatória depende da "habilidade" dos/as requerentes, porque ainda que um nome não conste da lista, o/a funcionário tem o poder de o acrescentar como admitido caso o considere adequado. Critérios como o potencial vexatório para a criança, ou uso de um nome antigo alguma vez usado em Portugal, podem ser fulcrais na admissão ou rejeição de determinado vocábulo nos balcões da Conservatória.
}

seja dada, o processo tem a sua morosidade e para a criança poder usufruir dos direitos de cidadania portuguesa é importante que Ihe seja imediatamente atribuído um nome admissível. Numa fase posterior, caso o nome enviado para análise seja aceite, será então possível requerer o averbamento de alteração de nome, conforme a alínea 5, artigo 104. ㅇ do Código do Registo Civil. É ainda possível requerer aos tribunais, caso não haja uma decisão positiva da Conservatória (Pinto, 2013: 6).

Ao observar as primeiras linhas de vocábulos admitidos na lista do IRN (tais como Araão, Abigail, Abdénago, Abdul, Abraão...), torna-se visível um padrão particularmente significativo atendendo ao contexto de um país da Europa do Sul: uma parte substancial dos nomes é de origem bíblica. Pinto (2013) explica que em 1496, após a ordem de expulsão de portugueses judeus e muçulmanos por D. Manuel I, tornou-se obrigatório o registo de batismos nos assentos paroquiais com nomes católicos portugueses. Este processo, a que o autor designa de "purificação onomástica", foi um projeto político que pretendia homogeneizar Portugal no que respeita à religião, cultura e linguística, reforçando assim o imaginário monocultural e monolinguístico da nação. Poder-se-ia, portanto, argumentar que a "purificação onomástica" iniciada no século XV é precursora de um projeto cultural disciplinador mais amplo, com ramificações nas identidades de género e sexuais que se mantêm até hoje. 
No século XIX, houve tentativas de alterar a política onomástica, com a aprovação em 1832 do registo para não católicos/as e abrindo-se os registos aos municípios (Pinto, 2013: 2). Já no século $X X$, com o regime republicano, tornou-se obrigatório o registo nas autoridades civis. O primeiro texto oficial sobre a composição do nome aparece no primeiro Código do Registo Civil (CRC), datado de 1911 (Diário do Governo, 1911). Este determina que o nome das pessoas deve constar dos nomes inseridos no calendário católico, sendo também permitido nomes de "pessoas conhecidas na história" e não devendo confundir-se com os nomes de família, "de cousas, qualidades, animaes, ou análogos" (art. 143. , CRC 1911) (Diário do Governo, 1911). O CRC de 1932 (artigo 242. ) manteve os critérios anteriores mas proibiu nomes ligados à política (Castro, 2001: 9). O CRC de 1958 acrescentou que os nomes próprios tinham de ser portugueses (Castro, 2001: 12). No CRC de 1967, para além de deixar de ser obrigatório nomes de santos ou figuras históricas, introduziu-se a permissão de nomes estrangeiros desde que adaptados à grafia e fonética portuguesa - um processo conhecido como de "aportuguesamento" -, sendo aceites nomes na forma originária se houver dupla nacionalidade ou se o/a registando/a for estrangeiro/a (Castro, 2001: 12). João Costa, linguista e Secretário de Estado da Educação aquando da entrevista realizada, descreve este processo da seguinte forma:
É a ideia que é defendida por muitos de que tendencialmente devemos aportuguesar palavras e tentar encontrar a versão portuguesa de palavras que são importadas. Isto muitas vezes decorre da inconsciência de que há imensas palavras que chegam ao português já por outras vias, não é? Inclusive nos nomes. (Entrevista 04/11/2016)

Após 1967 foram criadas exceções para crianças nascidas no estrangeiro ou filhas de estrangeiros/as ou com dupla nacionalidade. Em 2001, a Lei da Liberdade Religiosa permitiu que fossem registadas crianças com nomes próprios da religião professada pelos/as progenitores/as - artigo 8.․ alínea h (PGDL, 2001). Esta lei permite nomes islâmicos e hindus como Ajit, Dikshita ou Pruthviraj sem emissão de parecer especialista em onomástica nem adaptação gráfica (Castro, 2001; 2002). No entanto, a liberdade religiosa não confere consistência infalível no processo de nomeação. Relata João Costa, a partir de um caso real:

- Alguém que queria muito que o filho se chamasse Isaac e grafou diretamente com "q-u-e", e não foi levantado problema. Aportuguesou, não é?

— Um nome bíblico, haverá muitos...

- Exatamente! Agora, é daqueles casos que dá que pensar... Porque, se na bíblia, que está traduzida 
para português, Isaac se escreve com dois "as" e "c", porque é que quando a pessoa quer dar o nome da personagem bíblica ao filho tem de escrever de uma maneira diferente daquela que é escrita em todo o lado? Não é? Pronto, é um caso que mostra bem a arbitrariedade disto tudo. (Entrevista, 04/11/2016)

Verifica-se uma tendência para a laicização do nome próprio, com cada vez menos Marias da Piedade ou do Socorro, e cada vez mais Marias Helenas, ou Marias sem segundo nome próprio (Castro, 2002: 4). Estas alterações legais decorrem diretamente de um contexto sociocultural em mudança, tal como aponta Ivo Castro:

Sendo que a sociedade vai mudando, as necessidades vão mudando. Haver crianças estrangeiras ou filhos de estrangeiras a nascer cá, ou portuguesas a nascer lá, são realidades recentes e foi preciso dar conta disso. Haver outras religiões além da católica, quando há 50 anos só nomes de santos é que podiam ser dados, é uma mudança muito grande. (Entrevista, 29/08/2016)

Relativamente à legislação portuguesa sobre o registo de recém-nascidos/ as, quando o nascimento ocorre numa unidade de saúde (Artigo 101.--A, CRC de 1995), estas devem inserir em registo informático das unidades de saúde, IRN, I.P., e Instituto de Segurança Social, no prazo de 24 horas, os dados sobre o nascimento, incluindo data e hora de nascimento, o sexo do menor, e nome e residência da parturiente, mas não o nome da criança. Já o assento de nascimento deve contar, entre outros dados, com o sexo e o nome próprio e apelidos (artigo 102. ${ }^{\circ}, \mathrm{CRC}$ ).

Em relação à composição do nome, o artigo 103. ${ }^{\circ}$ do Código do Registo Civil de 1995 decreta o seguinte [realce nosso]:

$2-[\ldots]$

a) Os nomes próprios devem ser portugueses, de entre os constantes da onomástica nacional ou adaptados, gráfica e foneticamente, à língua portuguesa, não devendo suscitar dúvidas sobre o sexo do registando;

b) São admitidos os nomes próprios estrangeiros sob a forma originária se o registando for estrangeiro, houver nascido no estrangeiro ou tiver outra nacionalidade além da portuguesa;

c) São ainda admitidos os nomes próprios estrangeiros sob a forma originária se algum dos progenitores do registando for estrangeiro ou tiver outra nacionalidade além da portuguesa; [...]

4 - As dúvidas sobre a composição do nome são esclarecidas por despacho do director-geral dos Registos e do Notariado, por intermédio da Conservatória dos Registos Centrais.

Sobre a decisão da escolha do nome da criança, desde 1977, o Código Civil português determina que: 
ARTIGO 1875. (Nome do filho)

1. O filho usará apelidos do pai e da mãe ou só de um deles.

2. A escolha do nome próprio e dos apelidos do filho menor pertence aos pais; na falta de acordo decidirá o juiz, de harmonia com o interesse do filho.

3. Se a maternidade ou paternidade forem estabelecidas posteriormente ao registo do nascimento, os apelidos do filho poderão ser alterados nos termos dos números anteriores.

No que se reporta ao apelido, a regra é a criança ter pelo menos um dos apelidos dos ascendentes, usualmente um do pai e outro da mãe, quando inserida numa família nuclear tradicional, sendo que o apelido herdado do pai é o que, apenas por convenção cultural, conta como o mais importante e por isso fica registado em último lugar na ordem dos nomes. Sabemos, por exemplo, que em 2010 apenas 3\% das crianças nascidas foram registadas com o apelido da mãe em último lugar (Ferreira, 2010)2. Segundo a socióloga Ana Reis Jorge, "a maior parte das pessoas nem sabe que se pode colocar o nome da mãe em último lugar e por isso nem colocam essa hipótese" (Ferreira, 2010). Quando ocorre um casamento entre pessoas de sexo diferente, é também comum a mulher adotar o apelido do homem. Esta herança

Cf. notícia do Diário de Notícias em Ferreira (2010). Ficamos, no entanto, sem saber se dessa percentagem fazem parte crianças cuja paternidade não pode ser averiguada.. do apelido do homem tanto no nome da mulher como no nome da criança reflete o poder da autoridade masculina na conjugalidade e na família particularmente forte no contexto da Europa do Sul (Motta, 2007: 128), sendo esta prática patrilinear de nomeação uma forma de privilégio masculino (Eshleman e Halley, 2016). Mesmo quando se escolhe o apelido da mãe para último lugar no nome da criança, está-se a privilegiar a masculinidade do avô materno (Mills, 2003).

\section{Nome próprio- \\ marca de singularidade e marca de género}

To be called a name is one of the first forms of linguistic injury that one learns. But not all name-calling is in-

jurious.

Butler (1997: 2)

No livro Excitable Speech, Butler confronta-nos com a vulnerabilidade inerente à linguagem. Somos vulneráveis perante a linguagem como se ela tivesse capacidade de ação sobre nós e isto acontece porque somos seres formados nela. A primeira ferida linguística (linguistic injury) é o ato de nomeação, isto é, o ato de dar o nome às coisas ou aos seres. Este torna-se um evento traumático porque ocorre contra a vontade do sujeito nomeado: "é um ato que precede a minha vontade" (Butler, 1997: 38). É um ato recebido passivamente, mas indispensá- 
vel para se obter reconhecimento social, poder ser diferenciado das outras pessoas e obter direitos de cidadania. Conforme o IRN (2013), o "nome próprio é o elemento verdadeiramente individual do nome com que as pessoas são diferenciadas, é por ele que as pessoas são chamadas por familiares e amigos". O nome é, assim, simultaneamente um dos fatores que confere existência social (Butler, 2007: 2) e aquilo que nos distingue das outras pessoas dentro de uma rede de pertenças sociais (Pina-Cabral e Viegas, 2007b: 14). Não ter um nome é como não ter um rosto, é não ser reconhecida/o. Sem um nome, a criança recém-nascida não é cidadã, não tem direito à proteção do Estado. Conforme atentado em despacho pelo IRN, não tendo um nome a criança não tem direito a, por exemplo, assistência médica, programas de vacinação, subsídios familiares (IRN, 2009b: 5).

O cenário hipotético de alguém existir sem nome adquire contornos menos ficcionais quando consideramos a situação de crianças transgénero cujo nome oficial colide com a expressão de género. Este tema assume particular relevo num contexto em que o nome social - ou seja, a possibilidade de o sujeito decidir o nome pelo qual deseja ser tratado pelas instituições não obstante a informação oficial - não é ainda prática dominante em meio escolar. Atente-se no seguinte caso reportado por uma mãe de uma criança transgénero que entrevistámos em outubro de 2016. O André é um adolescente em pro- cesso de transição social de identidade. Por ser menor, não pode ainda mudar de sexo e nome legal. Todo o corpo docente o trata por André, e não pelo nome de registo. Quando o André mudou de escola, a mãe, por sugestão da psicóloga que o acompanha, pediu à Direção para que na pauta aparecessem apenas os apelidos do filho, com a retirada dos nomes próprios. A resposta que obteve foi a de que as pautas vinham feitas do Ministério da Educação e que não seria possível retirar os nomes próprios. Nesse ano letivo, na pauta, que é pública, o nome do André apareceu conforme o nome do registo, completo. Entretanto a mãe informou-se junto de pessoas dos serviços centrais de decisão do Ministério e descobriu que os/ as Diretores/as de Escola têm autonomia para decidir sobre que nome aparece na pauta, e como aparece. Então, no ano letivo seguinte voltou a fazer o pedido junto da Direção da escola para que constassem apenas os apelidos do André. A escola não concordou em manter apenas os apelidos e decidiu aplicar a medida que se aplica em caso de perigo para as crianças, medida essa que é não ter nome nenhum na pauta, como se não existisse. A hipótese de alguém existir sem nome adquire aqui um terreno empírico por excelência, e perante o qual existe uma grande invisibilidade com a complacência das instituições. A razão pela qual este caso, entre outros, aconteceu desta forma decorre do facto de não haver nenhuma norma formal escrita na qual se reconheça a pos- 
sibilidade de colocar na pauta apenas os apelidos ou o nome social. Essa ausência de informação oficial leva a que a Direção das escolas evite chamar a si essa responsabilidade, ainda que os/as Diretores/as da escola tenham poder para decidir sobre essa alteração ${ }^{3}$.

Acresce que, mesmo que alguém tome a decisão deliberada de não responder perante o chamamento do seu nome, o sujeito chamado continua a habitar uma determinada "posicionalidade social" (Butler, 2007: 33) que pode ser religiosa e de género: a simbologia do nome pode enquadrar-me numa religião que não escolhi para mim, bem como enquadrar-me numa identidade de género que não corresponde à minha. Podem acrescentar-se outras, como a classe:"receber um nome que faz parte do património onomástico da família é receber à nascença um símbolo de uma pertença", refere Antónia Lima (2007: 49) num estudo sobre a transmissão de nomes nas famílias de elite em Lisboa.

Uma vez que o nome, esta marca que nos distingue, foi recebido passivamente

\footnotetext{
3 No momento de escrita deste artigo, a comunicação social noticia declarações proferidas pelo ministro-adjunto Eduardo Cabrita garantindo que as escolas serão obrigadas a tratar as crianças e adolescentes pelo nome escolhido, independentemente de o processo de alteração formal ocorrer apenas depois dos 16 anos. Esta será uma das consequências das alterações à Lei de Identidade de Género presentemente em discussão, prevendo-se a sua aprovação ainda em 2017 (cf. Diário de Notícias, 24/01/2017, disponível em http://www. ilga-portugal.pt/noticias/893.php).
}

sem que tivéssemos oportunidade de participar no processo de escolha, argumentamos que o nome se trata de uma falsa marca de singularidade, já que singulariza um sujeito por vontade de outrem (Castro, 2001), e não por características pessoais. A contrastar com o nome próprio atribuído de forma externa está a alcunha, ou nome informal, igualmente atribuída de forma externa, mas sem o caracter formal do nome de registo, refletindo características desde o âmbito pessoal, como traços físicos ou comportamentais, a história familiar ou origem geográfica, profissão, entre outras (Marques, 1986). Resulta que o nome informal acaba por ser mais representativo da individualidade do que o próprio nome de registo (Pina-Cabral, 2008). Nas palavras de Maria Filomena Brito:

A alcunha, nome-outro forjado propositadamente para um indivíduo em concreto, inscreve-se num discurso de rigor, uma vez que o retrata fielmente aos olhos do grupo e o individualiza, cumprindo exemplarmente a sua função social. Há quem Ihe chame "o baptismo do povo". E, em todo o caso, o melhor "Bilhete de Identidade" (Brito, 1998: 846).

De importância similar à alcunha na função social encontra-se o nome social. O nome social é aquele escolhido pelas próprias pessoas para se apresentarem em público, podendo ser constituído por elementos tão diversos quanto uma al- 
cunha, um diminutivo, um pseudónimo, ou um nome próprio usado por pessoas transgénero que pretendem ser identificadas por um género diferente daquele designado à nascença. Nas palavras de Preciado, o nome social da pessoas transgénero é "o nome que assinalada o início de um processo de subjetivação dissidente" (Preciado, 2014). Se o nome é uma declaração de género, a alcunha ou nome social podem subverter esta lógica, introduzindo nuances e ambiguidade num projeto onomástico que contém na sua missão uma disciplina de género. A interpretação da nomeação enquanto prática disciplinar patriarcal e binária é partilhada pela sociolinguista Clara Keating, reportando-se ao Código de Registo Civil enquanto produto disciplinador do género:

O binarismo de género está perfeitamente inscrito no ADN do registo civil, está no discurso do registo civil, está incorporado e reflete essa impossibilidade [...] da identidade de género ser mais do que binária! [...] É uma representação, é um discurso que regulamenta esse binarismo. (Entrevista 21/09/2016)

Keating prossegue, refletindo em torno da ligação entre corpo e nome:

Quando tu mudas de nome, podes mudar o teu corpo ou tens essa possibilidade. Agora, não é o único lugar, não é? Não é o único lugar de transformação. Mas é um ponto de partida, digamos assim. [...] Não posso pensar o corpo sem pensar o nome. Se eu liberto o meu corpo, eu posso libertar o meu nome, não é? Mas às vezes o meu corpo está tão preso que só libertando-me do nome é que eu posso libertar o meu corpo. (Entrevista 21/09/2016)

Com efeito, se alguém se apresentar com um nome que não denuncia uma identidade sexual legalmente estabelecida, e se a essa apresentação corresponder um corpo sexualmente ambíguo, estamos perante a diluição do género enquanto elemento identitário inescapável. Para inverter a lógica da submissão à ferida linguística que denuncia parte da nossa história, podemos adotar um nome escolhido que reflita a outra parte da nossa história. Tal como um pseudónimo na componente subversiva que transporta, mas diferente dele, por visar conferir identidade em vez de a diluir, o nome social traduz uma reflexão sobre si próprio em vez de resultar da reflexão alheia à pessoa nomeada. Se, por um lado, o nome próprio confere identidade, por outro é um sintoma de perda de identidade. Por isso, e seguindo a linha de Butler, a nomeação pode ser um ato de violência quando não quero ser identificada pelo nome de nascimento, porque este nome não foi por mim escolhido e coloca-me numa posicionalidade simbólica de género na qual não me identifico. Por exemplo, numa situação relatada pela mãe do André, anterior à adoção do nome social, apesar 
de ser socialmente reconhecido por um rapaz devido à aparência física, quando o chamavam de Marta a sua "identidade" era revelada:

Quantas e quantas vezes nós íamos aos sítios e as pessoas confundiam-no com um rapaz e ele adorava, mas na altura ele ainda não tinha adotado o nome de André, nós chamávamos Marta e depois as pessoas ficavam a olhar para mim assim com um ar estranho e depois "ai, peço desculpa, peço desculpa" e eu dizia "não, não peça desculpa que ele está a adorar". (Entrevista, 14/11/2016)

Num polo oposto, eticamente mais responsável, situa-se o nome social que escolho para mim - no caso anterior, refere-se a "André" - e cujo respeito por essa escolha previne situações transfóbicas, tais como a recusa da escola em alterar na pauta o nome da criança transgénero.

\section{Disciplinando o corpo mutante: políticas de nomeação como ferramenta (cis)normativa}

You see, I've been through the desert on a horse with no name It felt good to be out of the rain In the desert you can remember your name

Cause there ain't no one for to give you no pain. "A horse with no name", America, 1971.
Anselm Strauss lembra que "um nome pode revelar muita coisa, tanto de quem o deu quanto de quem o porta" (1999: 35). A premissa teórica a partir da qual questionamos os dados recolhidos é-nos dada pela epistemologia crítica queer (Butler, 1990; Halberstam, 1998; 2011; Preciado, 2002; 2008) e pode ser formulada do seguinte modo: ao determinar juridicamente que o nome não deve "suscitar dúvidas sobre o sexo do registando" (sic) (artigo 103. do Código do Registo Civil), a política de atribuição de nome torna-se uma ferramenta do regime de sexo-género (Preciado, 2002) dominante que se caracteriza pela conformidade ao sexo atribuído à nascença. Essa conformidade compulsória é designada por cisnormatividade num contexto em que qualquer identidade transgénero é, por definição, fora da norma (logo, desviante, atípica, anormal). Ao definir como atípico todo o comportamento, prática ou corpo que se recusa a reproduzir o binarismo de género, estamos perante um regime cultural que reforça o lugar legítimo de uma norma socialmente construída através de poderes fácticos como a religião, a medicina ou a academia, entre outros. A partir de uma epistemologia crítica queer, sugerimos que a onomástica se tem constituído enquanto sistema de legitimação de um processo nacionalista, classista e cisnormativo. Para os objetivos a que nos propomos neste artigo, detivemo-nos nos elementos cisnormativos deste processo, ilustrando, a partir dos 
dados recolhidos, o modo como a heteronormatividade patriarcal inscrita no processo de nomeação produz efeitos de desidentificação pessoal e de reforço de um binarismo excludente.

Será possível uma prática queer de nomeação dentro do marco jurídico português? Pina-Cabral e Susana Viegas afirmam que o nome "não cancela a ambiguidade essencial da pessoa", sendo que, "reduzindo de facto a gama da variação possível, [...] nunca reduz a alteridade anterior de uma pessoa" (2007b: 29). Com base nas entrevistas realizadas, verificámos práticas de subversão, mais ou menos conscientes, das lógicas patrilineares que informam a tradição onomástica, sobretudo no que respeita aos apelidos $^{4}$. Incluem-se aqui a recusa da mulher em adotar o apelido do marido ou a decisão de atribuir a uma criança o apelido da mãe em último lugar. Como refere a sociolinguista Clara Keating:

o último nome é de homem, é patriarcal, é o do pai, digamos assim, mas há quem na segunda geração, na minha geração, utilize o nome da mãe, sabendo precisamente que isso é uma resistência, pois no uso prático é uma resistência àquela prática cultural que em Portugal existe que

\footnotetext{
${ }^{4}$ Para uma reflexão acerca de práticas de resistência e subversão entre pessoas trans adultas em Portugal relativamente ao nome próprio, ver Saleiro (2013). Neste trabalho Saleiro reporta-se à escolha de nomes próprios catalogados como neutros ou nomes que, estando catalogados como permitidos a um determinado sexo, são associados socialmente ao outro..
}

é a de usar o nome do pai no fim. (Entrevista, 21/09/2016)

Em casos de casais do mesmo sexo, a negociação não é tao óbvia como em casais de sexo diferente, que, à partida, seguem uma lógica patrilinear exceto em casos de prestígio do nome de família da mãe, onde se pode dar preferência por um apelido que suscite maior valor, conforme atentado por Ana Reis Jorge em entrevista ao DN (Ferreira, 2010). O que pode ser uma prática subversiva para um casal de sexo diferente pode não funcionar em casais do mesmo sexo. De acordo com Land e Kitzinger (2005), os casais de lésbicas muitas vezes não partilham o apelido. Quando existem crianças, a escolha pode depender de fatores como o já referido prestígio do apelido, mas também do facto de um dos membros do casal ser progenitor biológico da criança e optar-se por atribuir o seu apelido. Segundo um estudo realizado por Almack, as mães lésbicas que deram à luz num contexto de conjugalidade com outra mulher têm uma relação biológica de poder com as crianças no que respeita à escolha dos nomes (Almack, 2005).

O inquérito realizado por Eshleman e Halley (2016) a 26 mulheres mães, autoidentificadas como feministas e académicas, demonstrou que metade delas usa o apelido de origem, 10 usam o do marido, uma usa um nome que escolheu para si, e outra usa o apelido dela e o da companheira separados por um hífen. 
Apesar de metade das participantes não ter adotado o apelido do marido mesmo depois do casamento, apenas duas atribuíram às crianças o seu sobrenome, sendo que uma delas é mãe monoparental. Ou seja, a maioria destas mães feministas atribuiu às crianças o apelido do marido, com poucas exceções para a combinação da hifenização. No entanto, consideraram-se casos especiais, seja porque o seu apelido seria muito complicado, seja por pressão da família, seja por outro motivo que consideram não comprometer a sua identidade feminista. Segundo este estudo, os apelidos feministas atribuídos a crianças passam pela hifenização dos apelidos dos/ as progenitores/as, pela criação de um apelido de família igualitário ou, no caso exclusivo de casais de sexo diferente, pela atribuição do apelido da mãe. No entanto, estas práticas são raras. Em Portugal, não sendo possível alterar a forma do apelido, por exemplo, acrescentando o hífen para unir os dois últimos apelidos (maternos e/ou paternos), nem mesmo sendo possível criar um novo, resta apenas a hipótese de colocar como último apelido da criança o materno, subvertendo assim a lógica patronímica.

Segundo um estudo de Mills (2003), as mães feministas argumentam que a escolha pelo apelido do pai foi uma escolha estética e não política, permanecendo assim o privilégio masculino invisível. Quanto ao apelido, parece não haver escapatória, uma vez que a tradição tem uma lógica patrilinear e mesmo os sobrenomes das mulheres são herdados dos pais, no entanto, pode ir-se contrariando a patrilinearidade direta quando se faz o registo de um/a filho/a, preferindo o apelido da mulher para último lugar.

A dificuldade parece residir na escolha do nome próprio, mais do que na negociação dos apelidos. E porque uma epistemologia crítica queer não se restringe apenas às diferenças entre os sexos mas também dentro dos sexos, uma prática queer de nomeação pode passar por escolher um nome que não seja indiciador de género. No contexto de nomes portugueses essa tarefa é hercúlea, uma vez que que estes são marcados pela flexão de género. Os nomes permitidos na lista emitida pelo IRN foram em algum momento rejeitados e mais tarde aprovados. Basta um nome ter sido aceite uma vez para constar na lista, não significando, por isso, que aquele seja um nome conhecido, comum, ou que pertença a mais do que uma pessoa. Quando existem nomes marcados como M/F (raros e quase na sua totalidade com orientações para que sejam atribuídos como segundo nome para sexos específicos), tal não significa que sejam neutros ou comum de dois, isto é, atribuíveis da mesma forma ao género masculino e ao género feminino. Significa antes que, no momento do registo, foram entendidos como ambíguos quanto ao género ou atribuídos a um sexo que não seria o expectável. Por exemplo, o nome Gileade é um nome adaptado do mas- 
culino inglês Gilead; no entanto, está listado como M/F com indicação para que seja usado como segundo elemento de nome feminino (por exemplo, Ana Gileade). Desta forma, tendo já o marcador de género no primeiro vocábulo, o nome Gileade, quando precedido por Ana, já não suscitaria dúvidas quanto ao sexo, ao passo que se a criança tivesse apenas o nome Gileade podia ser confundida por uma pessoa do sexo masculino, já que este deriva de nome masculino. De acordo com a explicação do especialista João Silvestre, isto significa que, muito provavelmente, a pessoa que fez o pedido não sabia que o nome original era masculino e quis dar esse nome a uma criança do sexo feminino. Daí que este nome, masculino, possa ser atribuído a crianças do sexo feminino desde que colocado na segunda posição do nome, uma vez que a primeira é a que deve marcar o sexo. Assim, o nome Gileade funcionaria para o sexo feminino da mesma forma que João (por exemplo, Maria João).

O nome Mel é um nome permitido para o sexo masculino mas não para o feminino, apesar de, segundo João Silvestre, ser um nome que ultimamente tem sido pedido para crianças do sexo feminino. Mel foi admitido como nome masculino numa altura em que era associado a uma abreviatura do nome Melvin. No entanto, Mel também serve de abreviatura para Melanie ou Melissa, e é com base nesses nomes, e muito provavelmente por influência brasileira, que as pessoas querem agora registar as suas filhas com esse nome. Contudo, não o podem fazer porque Mel já foi prescrito para nome masculino. Prevê-se que quando um número considerável de cidadãs estrangeiras de nome Mel residirem em Portugal, ou quando houver um número considerável de pedidos nas conservatórias para o registo de nome Mel em crianças do sexo feminino, ele seja aceite.

Nicola é um dos raros casos listados como admitido para o sexo masculino e para o sexo feminino, sem indicação de ordem. No entanto, em Portugal Nicola é predominantemente masculino, tal como em Itália. Na Alemanha é feminino e em Espanha existe Nicolás, masculino.

Verifica-se portanto uma confluência de tradições onomásticas que confere familiaridade relativa a alguns vocábulos. 0 que usualmente acontece é estabelecer-se um padrão influenciado pelo primeiro requerimento. Tomemos como exemplo o nome Sidnei, derivado do inglês Sidney, comum de dois: foi adaptado à grafia portuguesa e categorizado na lista do IRN como nome masculino porque o primeiro requerimento a ser aceite aplicava-se a uma criança do sexo masculino. Os nomes ambíguos são estrangeiros, que devem ser adaptados fonética e graficamente à língua portuguesa. Se nesses vocábulos existia algum potencial subversivo à obrigatoriedade de ter um nome que não suscitasse dúvidas quanto ao sexo, este potencial é abalado no momento em que o nome é aceite 
e estabelecido como M ou F, de acordo com o sexo do primeiro ou primeira registanda a ser aceite. Atribuir um nome estrangeiro ou um nome religioso não católico é uma alternativa para aqueles/ as que professam outra religião darem às crianças nomes neutros que assim o sejam na língua original, mas quem não professa essa religião ou quem não tem dupla nacionalidade não tem esse poder de escolha. Nas palavras de João Silvestre:

A língua portuguesa pretende estabelecer um património onomástico tipicamente português. A introdução de terceiras vias corresponde geralmente à introdução de um nome estrangeiro. Claro que daqui a uns anos já há tantos nomes estrageiros em Portugal que já ninguém irá notar a diferença, mas por enquanto isso ainda não acontece. Ainda há uma consciência daquilo que são pares de nomes portugueses. Pares de oposição, masculino/feminino, Camilo/ Camila e não Camile. Enquanto o meio-termo representar um nome potencialmente estrageiro e isso for tido como algo a impedir, a questão continua. (Entrevista, 04/11/2016)

Atribuir o nome Nicola ou Zará passa por uma hipótese de fuga à denúncia do sexo, mas são apenas dois nomes, provavelmente de casos excecionais e isolados, e sendo que Nicola é reconhecido predominantemente como masculino não sortirá efeitos neutralizadores em casos isolados.
Parece-nos que a estratégia mais imediata de neutralização de um nome passa por adoção de nomes do género oposto para segundo elemento do nome, tal como de resto já acontece com nomes como Maria José, em que a pessoa - será do sexo feminino uma vez que assim o determina o primeiro vocábulo -, pode perfeitamente adotar a alcunha "Zé", e passa a ser "a Zé". Ou uma pessoa chamada Maria João que tem a liberdade de assinar com um nome feminino ou masculino, Maria ou João. O mesmo para Joana Afonso, entre outros. Nas palavras de João Silvestre, "são nomes masculinos que estão quase tornados neutros". Tendo um nome tipicamente masculino e outro tipicamente feminino, as pessoas podem adotar aquele em que se sentem mais confortáveis. No entanto permanece um problema que é a permanência numa bipolaridade de géneros, sem estarmos propriamente numa posição neutra. É aqui que entram os segundos nomes próprios, nomes "potencialmente neutralizadores" nas palavras de João Silvestre, que neutralizam o primeiro. Esses nomes potencialmente neutralizadores não são apenas o João ou o José. Muitos nomes terminados em "e" têm essa capacidade de nos confundir. A lista do IRN tem vários nomes que não estão tipificados como $\mathrm{M}$ ou F, pelo que não sabemos se são nomes que foram atribuídos a meninos ou meninas, nem se foram para a primeira ou segunda posição na ordem do nome. Vejamos o exemplo dado pelo linguista: Bru- 
ce. $O$ nome Bruce é um nome admitido que não tem indicação, na lista, quanto ao sexo. Não sabemos se tem sido atribuído a crianças do sexo masculino ou do sexo feminino. Mas se houver em Portugal 10 pessoas chamadas Bruce, das quais 5 são Maria Bruce e 5 são João Bruce, chegámos a um nome neutralizante do género. A potencialidade transgressora reside no segundo vocábulo. É no segundo vocábulo onde se podem encaixar os pedidos mais invulgares à conservatória, como por exemplo colocar um nome que é tipicamente apelido para segundo nome próprio. Conforme explicado por Ivo Castro, "se o primeiro cumprir as suas funções, o segundo nome próprio pode muito bem estar um bocadinho 'à solta'. Então é aí que pode haver umas afetividades, uns simbolismos, umas ligações, umas mensagens artisticamente colocadas pelos pais", de tal modo que se um pedido de nome for inicialmente rejeitado, pode haver negociações de forma a que esse nome seja colocado como segundo vocábulo. Como refere João Silvestre,

Se os pais decidirem atribuir aos seus filhos nomes que não sejam classificadores de expetativas sociais, têm a possibilidade de atribuir um segundo nome não necessariamente marcado quanto ao género e deixar que a pessoa use esse nome como entender. (Entrevista, 04/11/2016)

Fica assim, então, desvelada a potencialidade transgressora ou neutralizante do segundo nome. No entanto, esta potencialidade só será usufruída quando as questões da complexidade de género permearem a sociedade, da mesma forma que a multiplicidade de religiões tornou inevitável a aceitação de nomes religiosos estrangeiros. Aquilo que era irregular tem o poder de passar a ser norma, se a sociedade assim o quiser, porque, na onomástica portuguesa, é a sociedade que tem mudado a lei e não o contrário. Ivo Castro explica este movimento:

Uma irregularidade transforma-se em norma e num momento político oportuno a norma transforma-se em regra. Ou seja, enquanto norma é passiva, porque é o reconhecimento de um hábito coletivo que é reconhecido apenas porque é abundante, ocorre muito. A partir da aceitação política, então transforma-se em prescritivo, passa a ser um comportamento frequente, aceite, reconhecido e recomendado. (Entrevista, 29/08/2016)

\section{Considerações finais}

O Estado português é laico e proíbe a discriminação com base no sexo - artigo 13. da Constituição da República Portuguesa (AR, 2005) - e identidade de género - artigo 24. ${ }^{\circ}$ do Código do Trabalho (MTSSS, 2016). Contudo, nomes que suscitem dúvidas quanto ao sexo do/a registando/a têm de estar acompanhados de um ou- 
tro que não as suscite. Em contrapartida, nomes religiosos são admitidos e dispensam consulta por parte de um/a profissional de linguística. A arbitrariedade na admissão ou não admissão dos nomes no Registo Civil por parte do pessoal funcionário (Castro, 2001; Pinto, 2013) potencia "desigualdade no tratamento de escolhas idênticas" (Castro, 2001: 9), uma vez que um mesmo nome pode ser rejeitado por um funcionário e ser aceite por outro. Os nomes que são atribuídos às crianças dependem assim não apenas dos pais ou das mães, mas, sim, da vontade da pessoa que efetua o registo da criança na conservatória. Conforme denuncia Castro (2001), o problema não está nos funcionários em si mesmos mas antes no sistema que contém várias fragilidades, não garantindo o respeito nem pelos direitos das pessoas que requerem os nomes nem pela tradição onomástica portuguesa. Apesar do valor da onomástica portuguesa, de resto também defendida por João Silvestre, há que admitir que Portugal é um país cada vez menos monocultural e monolingue, as identidades são cada vez mais fluidas, não se justifica continuar a assentar num projeto que foi constituído para destruir a diversidade há cinco séculos. Conforme atenta Pinto (2013), vivemos num país que obriga as pessoas a registar os seus descendentes com vocabulários tradicionais que resultaram de uma mudança social forçada iniciada no século XVI; no entanto, não existe sequer um inventário completo dos nomes próprios admitidos por lei.
As mulheres carecem de poder na escolha dos sobrenomes dos/das filhas/ os porque, na esteira de uma tradição cultural dominante, prevalece uma heteronormatividade patriarcal naturalizada, invisível e, por isso, frequentemente inquestionável. A nomeação sexista é um problema que não se materializou, ainda, em exigências de maior igualdade por parte de decisores políticos e movimentos sociais. É necessária uma remodelação da estrutura cultural sexista em que nos movemos, e nessa reestruturação não pode ser descurada a reforma linguística - já iniciada por linguistas internacionais, como Dale Spender (1980), ou, em Portugal, por nomes como Graça Abranches (2000) ou Isabel Barreno (1985) -, uma reforma que se pretende inclusiva, não-machista, não-sexista, se possível não-binária, uma reforma que traduza a diversidade de experiências, práticas e identidades que caracteriza o tecido social. Desse caminho fazem parte políticas específicas na área da cidadania, da igualdade e da educação, como, por exemplo, a utilização do nome social relativo a crianças transgénero ou intersexo por parte da comunidade escolar, conforme proposta recente a ser discutida no parlamento português no momento em que escrevemos este artigo.

\section{Agradecimentos}

A investigação que informou este artigo foi financiada pelo European Re- 
search Council, através do seu 7. ${ }^{\circ}$ programa-quadro (FP/2007-2013)/ERC Grant Agreement "INTIMATE - Citizenship, Care and Choice: The Micropolitics of Intimacy in Southern Europe" [338452].

\section{Referências bibliográficas}

Abranches, G. 2000. Linguagem, Poder, Educação: o Sexo dos B, A, BAs. Lisboa, Comissão para a lgualdade e para os Direitos das Mulheres.

Almack, K. 2005. What's in a Name? The Significance of the Choice of Surnames Given to Children Born Within Lesbian-parent Families. Sexualities, 8(2): 239-254. DOI: 10.1177/1363460705050857.

AR - Assembleia da República. 2005. Constituição da República Portuguesa (2005). VII Revisão Constitucional. [Online]. [Lisboa], Assembleia da República. Disponível em: http://www.parlamento.pt/Legislacao/ Paginas/ConstituicaoRepublicaPortuguesa.aspx.

Barreno, M. I. 1985. O Falso Neutro: um estudo sobre a discriminação sexual no ensino. Lisboa, Rolim, Instituto de Estudos para o Desenvolvimento.

Bodenhorn, B.; Vom Bruck, G. 2006. The Anthropology of Names and Naming. Cambridge, Cambridge University Press.

Breen, R. 1982. Naming practices in Western Ireland. Man, 17(4): 701-713. DOI: 10.2307/2802041.

Brito, M. F. C. 1998. A alcunha: configuração linguística de um continuum afectivo (observação de uma micro-sociedade de tipo clânico). Hvmanitas, L: 835-866. Disponível em: https://www.uc.pt/fluc/ eclassicos/publicacoes/ficheiros/humanitas50/48.2_Carvalho_Brito.pdf.

Butler, J. 1990. Gender Trouble: Feminism and the subversion of identity. New York, Routledge.

Butler, J. 1997. Excitable Speech: a Politics of the Performative. London, Routledge.

Butler, J. 2007. Undoing Gender. New York, Routledge.

Castro, I. 2001. O Nome dos Portugueses. Conferência no Encontro comemorativo dos 25 anos do Centro de Linguística da Universidade do Porto. [Online]. Disponível em http://www.clul.ulisboa.pt/files/ivo_castro/2001_Nome_dos_Portugueses.pdf.

Castro, I. 2002. A Descensão de Maria. Colóquio de Antroponimia Galega. Santiago de Compostela, Setembro 2002. Disponível em: http://www.clul.ul.pt/files/ivo_castro/2002_Descenso_de_Maria.pdf.

Diário do Governo. 1911. Código do Registo Civil, Ministério da Justiça: número 41 de 20 de Fevereiro de 1911. [Online]. [Lisboa], Diário da República Eletrónico. Disponível em: https://dre.pt/application/dir/pdfgratis/1911/02/04100.pdf.

Durkheim, É.; Mauss, M. 1984. Algumas formas primitivas de classificação. Durkheim: Sociologia. S. Paulo, Ática: 183-203.

Eshleman, A.; Halley, J. 2016. Self-Identified Feminist Mothers' Naming Practices for Their Children: Accepting Being "as Feminist as Everyone" Else. Women's Studies, 45(3): 215229. DOI: 10.1080/00497878.2016.1149033. 
Ferreira, A. B. 2010. 3\% dos bebés registados com último nome da mãe. [Online]. [Lisboa], Diário de Notícias, 22 de novembro de 2010. Disponível em: http://www.dn.pt/ portugal/interior/3-dos-bebes-registados-com-ultimo-nome-da-mae-1717120. html.

Halberstam, J. 1998. Female Masculinity. Durham, NC, Duke University Press.

Halberstam, J. 2011. The Queer Art of Failure. Durham, NC, Duke University Press. DOI: 10.1215/9780822394358

IRN-Instituto dos Registose do Notariado.2009a. Recurso hierárquico. Admissibilidade do vocábulo "MIA". [Online]. [Lisboa], Instituto dos Registos e do Notariado. Disponível em: http://www.irn.mj.pt/IRN/sections/ irn/doutrina/pareceres/civil/2008/p-rc07-2008-sjc-ct/downloadFile/file/pcc0072008.pdf?nocache=1318861841.94.

IRN - Instituto dos Registos e do Notariado. 2009b. Vocábulos Admitidos ou Não Admitidos como Nomes Próprios. [Online]. [Lisboa], Instituto dos Registos e do Notariado. Disponível em: http://www. irn.mj.pt/IRN/sections/irn/a_registral/ registos-centrais/docs-da-nacionalidade/ vocabulos-admitidos-ou/.

IRN - Instituto dos Registos e do Notariado. 2013. Composição do nome. [Online]. [Lisboa], Instituto dos Registos e do Notariado. Disponível em: http://www.irn.mj.pt/ IRN/sections/irn/a_registral/registo-civil/ docs-do-civil/dar-o-nome/.

Land, V:; Kitzinger, C. 2005. Speaking as a Lesbian: The Heterosexist Presumption. Research on Language and Social Interaction, 38(4): 371-416. DOI: 10.1207/s15327973rlsi3804_1.
Lima, A. P. 2007. Intencionalidade, Afecto e Distinção: as Escolhas de Nomes em Famílias de Elite de Lisboa. In: Pina Cabral \& Viegas (orgs.) Nomes: Género, Etnicidade e Família. Coimbra, Almedina: 39-62.

Lopes da Silva, A. 1984. A antropologia e os estudos de nomes pessoais e sistemas de nominação. Dédalo, 23: 235-254.

Marques, C. 1986. O estudo antropologico das alcunhas. Revista Lusitana (Nova Série), 7: 125-145. Disponível em: https://www. academia.edu/12732728/O_estudo_antropologico_das_alcunhas.

Mills, S. 2003. Caught Between Sexism, Anti-sexism and "Political Correctness": Feminist Women's Negotiations with Naming Practices. Discourse \& Society, 14(1): 87-110. DOI: 10.1177/0957926503014001931.

Motta, F. M. 2007. Em Nome do Pai e em Nome da Mãe: Gênero e Significado no Estudo dos Nomes. In: Pina Cabral, J.; Viegas, S. (eds.) Nomes: Género, Etnicidade e Família. Coimbra, Almedina: 121-144.

MTSSS - Ministério do Trabalho, Solidariedade e Segurança Social. 2016. Código do TrabaIho Versão atualizada de Agosto 2016. [Online]. [Lisboa], Comissão para a Igualdade no Trabalho e no Emprego. Disponível em: http://cite.gov.pt/pt/legis/CodTrab_ indice.html?

PGDL - Procuradoria-Geral Distrital de Lisboa. 2001. Lei da Liberdade Religiosa — Lei n.o 16/2001, de 22 de Junho. [Online]. [Lisboa], Procuradoria-Geral Distrital de Lisboa. Disponível em: http://www.pgdlisboa.pt/leis/lei_mostra_articulado. php?artigo_id=806A0008\&nid $=806$ 
\&tabela $=$ leis\&pagina $=1 \&$ ficha $=1 \&$ so $_{-}$ miolo $=\&$ nversao $=\#$ artigo.

Pina-Cabral, J. 2008. Recorrências antroponímicas lusófonas. Etnográfica, 12(1): 237-262. DOl: 10.4000/etnografica.1684.

Pina-Cabral, J.; Viegas, S. 2007a. Nomes: Género, Etnicidade e Família. Coimbra, Almedina.

Pina-Cabral, J.; Viegas, S. M. 2007b. Nomes e Ética: uma Introdução ao debate. In: Pina Cabral, J.; Viegas, S. Nomes: Género, Etnicidade e Família. Coimbra, Almedina: 13-38.

Pinto, P. F. 2013. Purificação onomástica e mudança social em Portugal. Seminário/ Webinário, Política de Língua, Planeamento Linguístico e Mudança Social, Lisboa. Disponível em: http://hdl.handle. net/10400.2/2814.

Plummer, K. 2003. Intimate Citizenship. Private Decisions and Public Dialogues. Seattle, WA, University of Washington Press.

Preciado, B. 2002. Manifiesto contra-sexual. Prácticas subversivas de identidad sexual. Madrid, Editorial Opera Prima.

Preciado, B. 2008. Testo Yonqui. Madrid, Ed. Espasa.

Preciado, B. 2014. Marcos for ever. [Online], Parole de Queer. [Consultado em 7-03-2017]. Disponível em: http://paroledequeer. blogspot.pt/2014/06/desprivatizar-el-nombre-propio-deshacer.html.

Roseneil, S. 2010. Intimate Citizenship: A Pragmatic, Yet Radical, Proposal for a Politics of Personal Life. European Journal of Women's Studies, 17(1): 77-82. DOI: 10.1177/13505068100170010603.

Saleiro, S. P. 2013. Trans géneros: uma abordagem sociológica da diversidade de géne- ro [Online]. Tese de Doutoramento em Sociologia, Instituto Universitário de Lisboa. Disponível em: http://hdl.handle. net/10071/7848.

Santos, A. C. 2013. Social Movements and Sexual Citizenship in Southern Europe. Basingstoke, Palgrave-Macmillan. DOI: $10.1057 / 9781137296405$.

Spender, D. 1980. Man Made Language. London: Routledge.

Strauss, A. 1999. Espelhos e Máscaras: A Busca de Identidade. S. Paulo, EdUSP. 